\title{
Environmental monitoring using bioassays
}

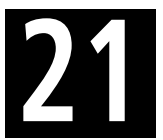

\author{
Nils G.A. Ekelund ${ }^{1}$ and Donat-P. Häder ${ }^{2}$ \\ ${ }^{1}$ Malmö University, Malmö, Sweden, ${ }^{2}$ Friedrich-Alexander University, Erlangen-Nürnberg, \\ Germany
}

\subsection{Introduction}

The degree and rapid deterioration of water quality in aquatic ecosystems has been in the focus for many decades since the growth of industrial activity and use of many environmental toxicants. The problems with public health caused by water pollution were already recognized in the early 1800 s and at this time the first legislation was made as a consequence to water pollution [1]. Even during the 21st century it is one of the greatest challenges to achieve more sustainable water management, which is among many countries in Europe recognized by the Water Framework Directive (WFD). Until the 1990s in Sweden, untreated wastewater from the pulp and paper industries caused extensive pollutions in coastal aquatic ecosystems [2]. Today the situation has improved in developed countries indicating that less untreated wastewater is discharged into aquatic environments. In developing countries the amount of effluent or untreated wastewater into water sources is still very high. The large quantities of wastewater contain toxic metals, organic and inorganic pollutants, which all could be harmful for organisms in aquatic environments [3]. Even if acute lethality caused by pollutants and chemical compounds in aquatic ecosystems has become rare there is still a significant risk for negative effects on ecosystems even if the levels of the chemicals are low [4]. The low levels and high complexity of chemical compounds are nearly impossible to monitor and regulate which makes it even more important to develop methods to evaluate contamination to aquatic ecosystems $[4,5]$.

One of the components that play a decisive role in the pollution of aquatic ecosystems is the ongoing urbanization. It is the change of land use and agricultural activities which increases the amount of fertilizers, pesticides, herbicides, and chemical compounds of different origin that contaminate water bodies. The use of herbicides in agriculture and forestry has increased during the last decades [6,7]. Due to the water solubility of herbicides the breakdown products are often found in aquatic ecosystems where they have the possibility to affect nontarget algal species [7]. In Portugal Primextra Gold TZ is one of the best-selling herbicides and for the synthesis of this pesticide copper is used [8]. The two main active ingredients in Primextra Gold TZ are terbuthylazine (TBA) and S-metolachlor where TBA inhibits photosynthesis in photosystem II (PS II) and S-metolachlor blocks cell division and cell enlargement [8]. The effects and damage on species and 
ecosystems from pollutants like Primextra Gold TZ do not only show the complexity of the compound itself with different active ingredients and heavy metals but are also related to the use of herbicides in agricultural areas near aquatic systems. Impacts from pollution on aquatic systems differ depending on whether the outlet into the aquatic systems is from point sources or from nonpoint sources [9]. It is more straightforward and easier to use ecotoxicological test assessments of point sources than of nonpoint sources where the complexity is higher due to multiple stressor effects [10].

A group of compounds which are a part of all pollutants are heavy metals. The pollution of heavy metals is strongly related to industrial development and these compounds cannot be easily detoxified, which results in their persistence in the environment [11]. Even if most of the heavy metals are toxic they also act as essential elements in the living system and for cellular metabolism and growth [12]. Living organisms require trace amounts of some metals, although increased levels of these compounds may be highly toxic $[13,14]$. The group of heavy metals contains copper $(\mathrm{Cu})$, zinc $(\mathrm{Zn})$, lead $(\mathrm{Pb})$, chrome $(\mathrm{Cr})$, nickel $(\mathrm{Ni})$, cobalt $(\mathrm{Co})$, arsenic (As), and mercury ( $\mathrm{Hg})$. Some of these elements have also been found in the wood ash, which is derived from different biofuel sources in the forest industry [15]. Metal ions may also bind to soil particles but additionally to components of herbicides like glyphosate [16].

The contamination of aquatic ecosystems with heavy metals affects the organisms within this ecosystem in the way that heavy metals tend to be taken up by the organisms. Microalgae, which are the primary producers and the basis of the food chain in aquatic systems, are one of the first groups to be contaminated by the pollution. The effects of excess heavy metals on microalgae are suppression of photosynthesis, cell growth, chlorophyll synthesis, and motility [17]. Since microalgae are the first step in the food web, the contamination affects other organisms on a higher level in the food chain. A change in microalgae populations or in their chemical composition due to contamination may have a harmful impact on higher trophic levels in the environment [8]. As microalgae are very sensitive to toxic elements they could be used as an early warning system when monitoring pollution. The advantage of using microalgae is that there is no need to consider ethical constraints associated with higher organisms such as vertebrates when testing toxicity of different compounds [18]. The important role of microalgae is not only of interest for environmental monitoring but also within the fields of waste treatment, biodiesel production, and the use of biomass to obtain commercial products.

\subsection{Bioassay tests}

During the last years the need for monitoring aquatic ecosystems in order to evaluate and manage the risk of environmental damage has led to the development of a number of different bioassay tests. These toxicity tests use a range of microorganisms, algae, invertebrates, and fish [19-21]. To detect biological effects often small 
scaled biological systems on a molecular level, cellular (in vitro) or whole organism (in vitro) levels are being used [4]. The main aim is to generate protocols for toxicity, standards and limits imposed by regulators which are fast and economical. Bioassay methods are therefore based on the response of living organisms in order to analyze and evaluate potential effects of toxicants. In order to improve the ecological relevance of these tests it is of great importance to establish a scientific base when extrapolating from bioassay tests in the laboratory to field situations [22].

When using microalgae in bioassays the dominant parameters for study are physiological responses. Single-celled algae are very sensitive to toxic compounds and this makes it possible to identify the presence of a pollutant above a potentially harmful threshold, which is important when determining the suitability of the bioassays. In addition to the sensitivity of microalgae to toxicity, the cells respond more quickly than larger organisms, have a short generation time, and are easy to handle. The cells are small and only separated from the surrounding toxic medium by membranes or a cell wall, which enables rapid uptake of toxic compounds by their cells [23]. The high diversity of microalgae makes toxic effects of aquatic pollutants very heterogeneous due to the complexity and interactions between species, physiological responses, and environmental factors.

Physiological parameters such as photosynthesis, quantum yield, chlorophyll content, growth, motility, and fluorescence respond differently to pollutants and therefore it is of high value to set the criteria of the toxicity for the bioassays. The criteria include the standardization of culture medium and conditions and experimental parameters [24]. Factors which could affect the toxicity of a compound are physico-chemical properties such as $\mathrm{pH}$, temperature, and light (irradiance and exposure time) [25]. Other biomarkers which have been proven to be excellent when studying environmental stressors are biomolecular and biochemical measures $[8,9]$.

There is an urgent need for the development of early warning systems that can monitor, detect, and evaluate effects of toxicants and are rapid, reliable, and sensitive to a wide range of compounds. However, it must be pointed out that there are some problems concerning the evaluation of laboratory studies in relation to the effects of stressors on the health of aquatic ecosystems [9]. One important issue is to assess the ecological significance of laboratory early-warning indicators and to establish cause and effects relationships between specific stressors and the types and levels of environmental pollution and damage [9]. Fast responses could be observed either within hours or even during short-term incubation within minutes. Ahmed and Häder [26] defined end points for short tests after 0-24 h, and for long-term tests after 1-5 days. In a study by Pettersson and Ekelund [6] the shortterm tests were $3 \mathrm{~min}$ and the long-term tests were 7 days when studying the motility in Euglena gracilis. Short-term and small-scaled bioassays are generally favored over long-term, large-scale bioassays [4].

A fast method is the noninvasive measurement of the in vivo fluorescence which facilitates monitoring of activity changes affecting PS II in microalgae. Fluorescence is one of three processes where the energy from light absorption by chlorophyll molecules is re-emitted as red fluorescence [7]. The two other processes 
are photochemistry and dissipation of the excess energy as heat. The degree of fluorescence indicates the quantum yield of both photochemistry and heat emission from living cells. Brayner et al. [27] used biosensors when studying the effects of herbicides on three different green microalgae; the best results and most accurate responses were obtained with Dictyosphaerium chlorelloides.

One of the main advantages of quantifying fluorescence from single cells is that it does not require any preparation of the algae. Toxicity effects of the tested chemicals, even at low concentrations, can be obtained after 20 min of incubation [28]. The rapid techniques of pulse amplitude modulation (PAM) fluorometry [29] has a great advantage because it provides direct information on the photosynthetic activity of the algae, in comparison to measurements of cell numbers which requires several hours of incubation [7,26,30]. Other tests with microalgae and photosynthesis which are defined as short-term tests use $6 \mathrm{~h}$ to monitor and evaluate the toxic effects of metals [31].

In a study by Ahmed and Häder [17] PAM fluorescence was used for measurements of both photosynthetic yield and electron transport rate (ETR) when evaluating the effects of nickel and cadmium of photosynthetic parameters of E. gracilis. The duration of exposure to heavy metals at different concentrations varied from direct $(20 \mathrm{~min})$ exposure to long-term exposure of 5 days. The long-term monitoring using days was initiated because of the fact that heavy metals are nondegradable pollutants with an ability of bioaccumulation. Similar photosynthetic parameters were used in a study by Ekelund and Aronsson [32] where E. gracilis was shown to be more resilient to high $\mathrm{pH}$ than the green alga Chlamydomonas reinhardtii after 7 days at different concentrations of non-pH adjusted wood-ash solutions.

Another rapid method based on photosynthetic activity which is used in environmental monitoring is the use of biosensors that reflect the real physiological impact of active compounds [33]. A biosensor can be defined as an integrated bioreceptorphysicochemical transducer device which consists of different elements: a bioreceptor or biological recognition element, which interacts with the pollutant molecules, a physicochemical transducer, which converts the biological response into a detectable physicochemical signal, and a microelectronic processor of this signal, which amplifies it and converts it into a numeric record [13]. Promising investigations using biosensors for photosynthetic activity and PS II could be attractive and sensitive enough when studying the effects of chemical pollutants [33]. The effects of pollutants or chemical compounds using biosensors will modify the signal from the photosynthetic activity [27].

To identify the toxicity of a substance in different organisms requires the determination of a predicted no-effects concentration (PNEC) [34,35]. The PNEC for a substance is regulated by the European Commission [5]. The PNCE data are obtained in short-term tests using common endpoints. Common endpoints for the assessment of toxicity for algal growth tests and photosynthetic activity in microalgae are the proportion of the dead algae or the photosynthetic activity after a defined exposure time to the toxic compound. This could either be described as an $\mathrm{EC}_{50}$ value, which is the concentration of the test substance that results in a $50 \%$ inhibition [36], or by a the NOEC (No Observed Effect Concentration) value [37], 
which is the highest tested concentration at which no significant inhibition occurs $[6,22,38] . \mathrm{EC}_{50}$ and NOEC values are important values for the application of environmental quality standards.

Besides the common bioassay parameters of photosynthesis and growth of microalgae, swimming behavior of phytoplankton organisms is a reliable parameter for ecotoxicological tests when studying the effects of water quality. Swimming behavior has been observed in a broad context from ecological phenomena, phototactic orientation, physical stratification, avoidance, and sex [18]. Feng et al. [18] argue that the swimming behavior of microalgae can be used as a sensor for environmental signals and a link between biochemical processes and consequences on the ecosystem level. One method which has been used to identify toxicity effects on the motility of microalgae is the determination of toxicity by using different types of chips. A chip can be used to perform many parallel tests simultaneously [18].

A method based on image analysis that operates in real time and tracks the numbers of motile cells is ECOTOX [39-41]. The effects of wastewater, heavy metals, herbicides, and other pollutants are evaluated with the ECOTOX system by using the parameters motility and orientation of E. gracilis $[3,6,42]$.

\subsection{ECOTOX}

Using the ECOTOX method allows for calculating the number of motile cells, the percentage of cells moving upwards (gravitaxis), the mean velocity, the compactness (form factor, which is the ratio of the circumference to the area normalized to a circle) of the cells, and the precision of orientation ( $r$-value) (cf. Chapter 10: Ecotox, this volume). The system operates in real time and tracks of up to 1500 cells in parallel. The cells of E. gracilis are pumped into an observation chamber. This chamber could hold up to $10^{6}$ cells $\mathrm{mL}^{-1}$ and the test sample of toxic compounds can be automatically diluted with increasing dilutions of 1:1, 1:3, 1:7, 1:15, and $1: 31[6]$.

An important factor before starting a measurement is the filling time of the cuvette. This time must be long enough that fresh cells of E. gracilis are transferred from the reservoir where the cells are located before the beginning of the measurement. The tracking time of the analysis shows variations but is often within in the range of 3 to $5 \mathrm{~min}$. Depending on the cells being used in the ECOTOX system there is a need to set minimum and maximum areas of the cells. The setup of areas makes it possible to exclude debris or other species which may be contained within in the sample cuvette. The setup of a minimum speed of the organisms is of importance because it allows distinguishing between dead or nonmotile cells and active motile cells. In a study by Pettersson and Ekelund [6] cells were considered motile when they moved at $7 \mu \mathrm{m} \mathrm{s}^{-1}$ or faster but in a study by Azizullah et al. [3] the minimal velocity was chosen as $15 \mu \mathrm{m} \mathrm{s}^{-1}$. Within the system there is also a possibility to set different incubation times in darkness before measurements start. 


\subsection{Short-term vs long-term tests}

ECOTOX measurements of the effects of herbicides using E. gracilis in short-term tests of 0,30 , or $60 \mathrm{~s}$ showed strong effects on the velocity and upward swimming at concentrations higher than $1.25 \mathrm{~g} \mathrm{~L}^{-1}$ [6] (Fig. 21.1). The results showed different effects dependent on what type of herbicide was used. Avans had a stronger effect than Roundup. Avans showed lower NOEC values than Roundup for the different parameters but after 7 days (long-term) the NOEC values were similar except for upward swimming.

However, the effects on motility were less pronounced; this is probably due to the fact that cells of E. gracilis were still motile but that the orientation behavior was affected. In a study by Azizullah et al. [3] the gravitactic orientation of E. gracilis showed similar negative effects when exposed to wastewater. In comparison to cell shape and motility the gravitactic orientation was significantly impaired. The variation in sensitivity to pollutions of the different parameters in E. gracilis indicates that gravitactic orientation and cell shape are dependent of each other. Several studies show discrepancies between the effects of pollution on motility, cell shape, speed, and gravitactic orientation, which could be the result of changes in density between the cell body and the surrounding medium. Gravitactic orientation shows stronger negative effects when exposed to pollution which alter the density thus impairing the capacity to orient in the water column. In contrast to motility, velocity of E. gracilis showed a strong inhibition after short tests of only 30 and $60 \mathrm{~s}$ incubation with herbicides (Fig. 21.2) [6]. The effects were most pronounced with Avans and less with Roundup.

When testing the effects of industrial wastewater on E. gracilis the most sensitive parameters were gravitactic orientation and cell compactness [43]. The content of industrial wastewater is very complex depending on the large amount of different pollutants and toxic compounds. This complexity of wastewater makes it difficult to relate an impairment of motility parameters to a specific compound. Heavy metals which can occur in wastewater have different effects on motility parameters. After $24 \mathrm{~h}$ exposure to different heavy metals the motility and cell shape of E. gracilis showed no significant negative effects at the different concentrations (Table 21.1) [44].

Probably the concentrations were too low and the exposure time too short to induce significant effects of the different heavy metals. However, in a study with the heavy metals nickel $(\mathrm{Ni})$ and cadmium $(\mathrm{Cd})$ the effects were stronger after $24 \mathrm{~h}$ in comparison to tests immediately after exposure [17]. The $\mathrm{EC}_{50}$ values for upward swimming showed large differences, and the value after direct exposure was $292 \mathrm{mg} \mathrm{L}^{-1}$ and after $24 \mathrm{~h}$ incubation was $12.7 \mathrm{mg} \mathrm{L}^{-1}$. The results from this study showed that longer incubation times did not show any significant difference for the different parameters, indicating that shorter incubation times are recommended for toxicological studies. However, it was concluded that acute toxicity is useful for rapid assessment but not enough to produce pronounced inhibition for all parameters [41].

Like wastewater, wood ash solutions contain toxic compounds [15]. Many different heavy metals are found in wood ash and the most common compound is cadmium $(\mathrm{Cd})$. The potential release of these compounds into forest ecosystems 


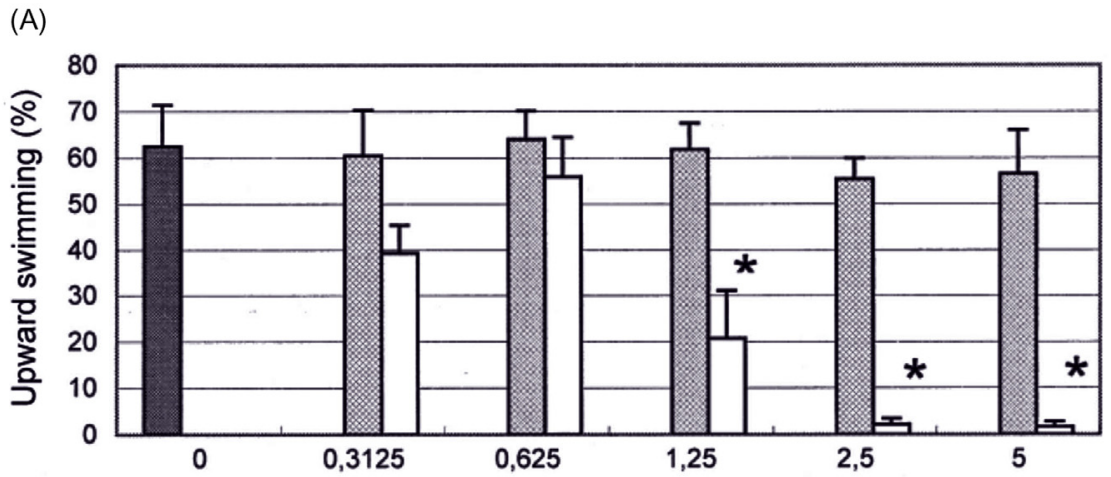

(B)

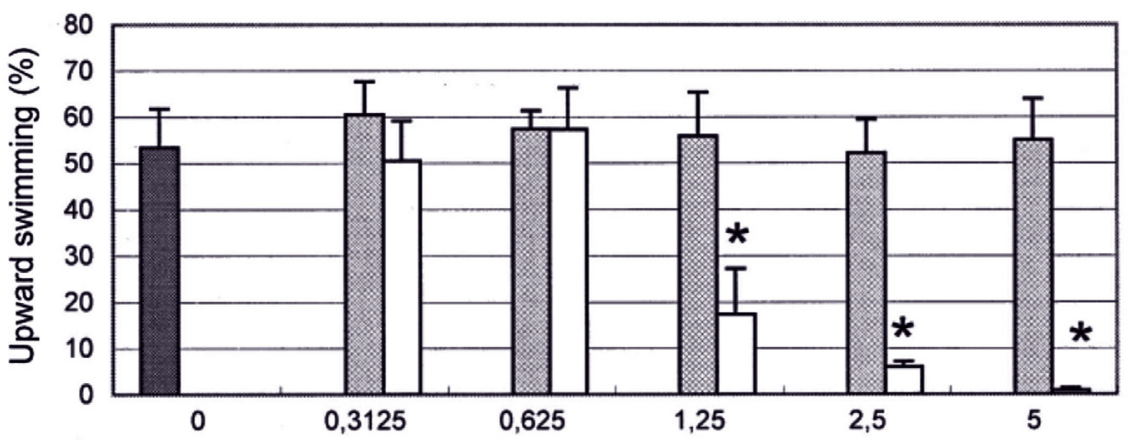

(C)

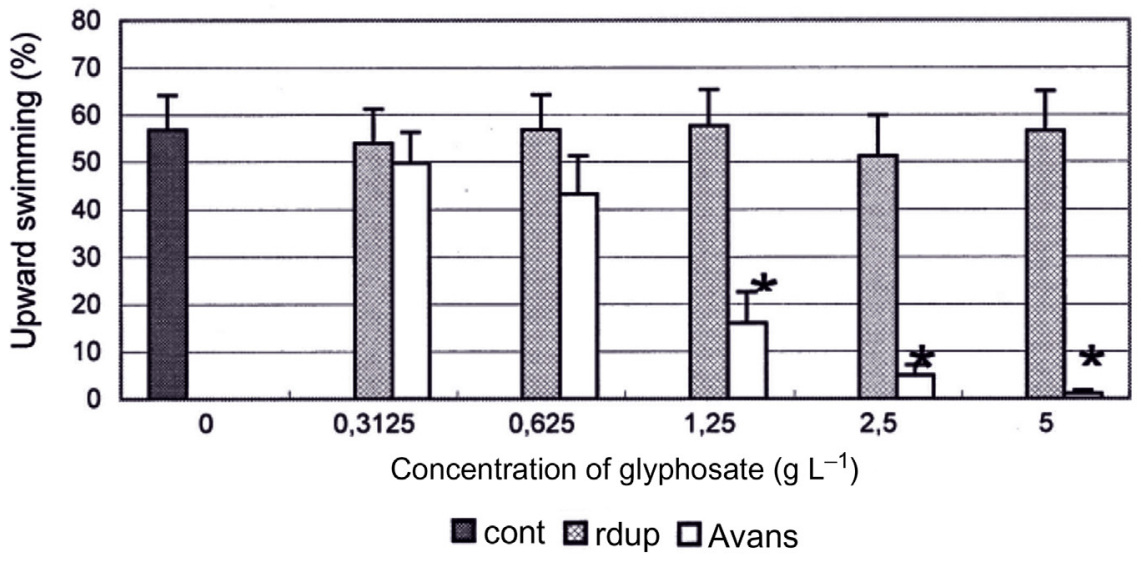

Figure 21.1 Upward swimming (\%) of Euglena gracilis at different concentrations $\left(\mathrm{g} \mathrm{L}^{-1}\right)$ of glyphosate with the herbicides Roundup (rdup) and Avans after different incubation times of 60 (A), 30 (B), and $0 \mathrm{~s}$ (C). Control (cont) tests are made without the addition of glyphosate. Columns indicate mean values with standard deviation, and asterisks indicate statistical significance between treatment and control.

Source: From Pettersson M, Ekelund NG. Effects of the herbicides Roundup and Avans on Euglena gracilis. Arch Env Contamin Toxicol 2006;50(2):175-181 with permission. 
(A)

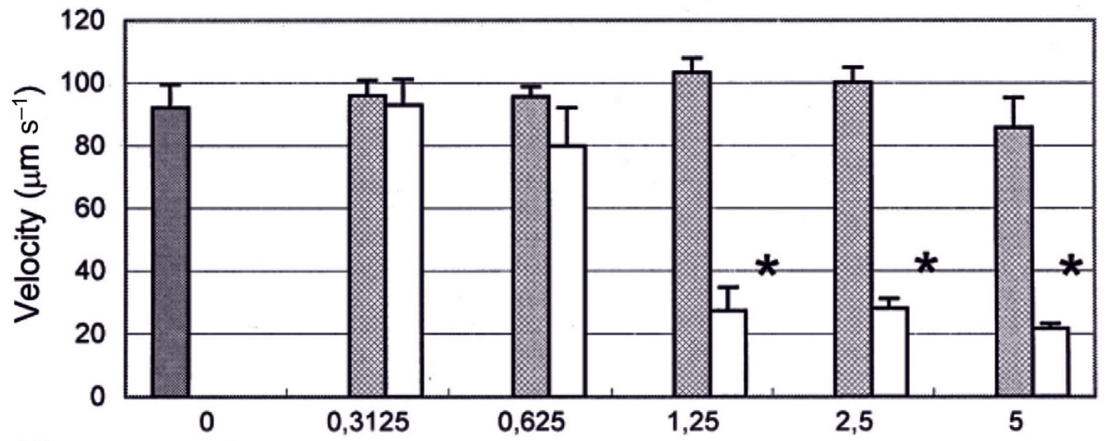

(B)

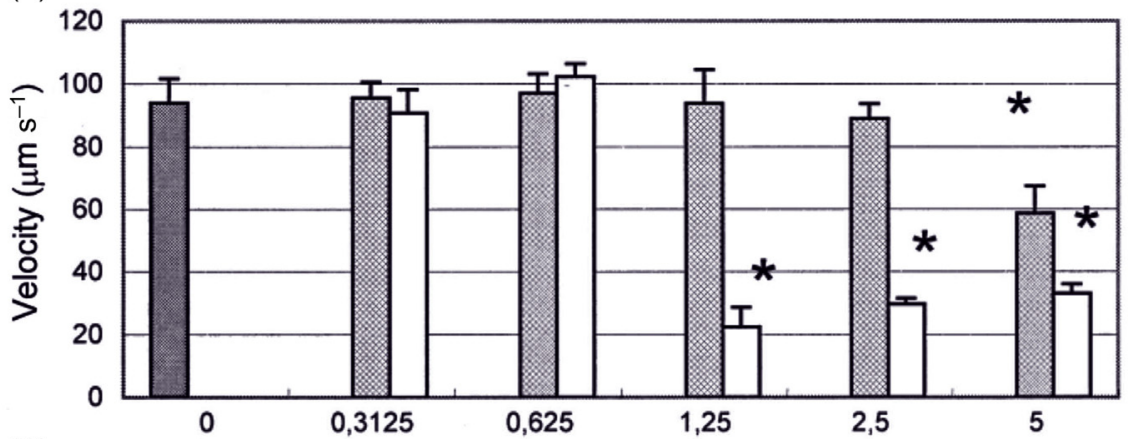

(C)

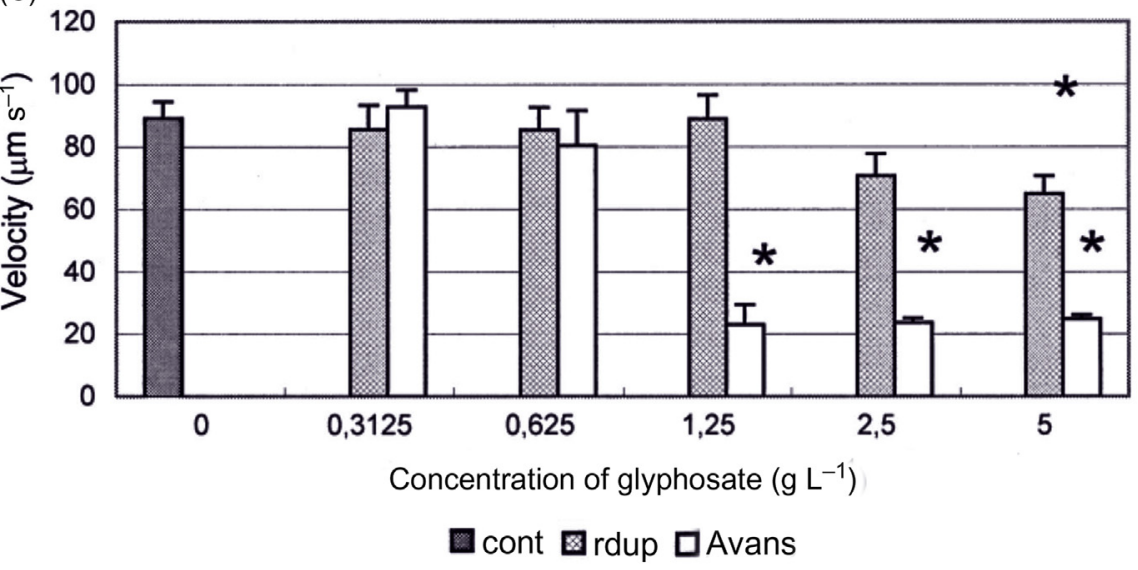

Figure 21.2 Velocity $\left(\mu \mathrm{m} \mathrm{s}^{-1}\right)$ of Euglena gracilis at different concentrations $\left(\mathrm{g} \mathrm{L}^{-1}\right)$ of glyphosate with the herbicides Roundup (rdup) and Avans. Short-term tests with different incubation times of 60 (A), 30 (B), and 0 (C). Control tests are made without the addition of glyphosate. Columns indicate mean values with standard deviation, and asterisks indicate statistical significance between treatment and control.

Source: From Pettersson M, Ekelund NG. Effects of the herbicides Roundup and Avans on Euglena gracilis. Arch Env Contamin Toxicol 2006;50(2):175-181 with permission. 


\section{Table 21.1 Effects of different concentrations of heavy metals and pentachlorophenol (PCP) on the cell shape (circularity) of Euglena gracilis after $24 \mathrm{~h}$ exposure.}

\begin{tabular}{|l|l|l|l|l|l|}
\hline \multirow{2}{*}{ Concentration $\left(\mathbf{m g ~ L}^{-\mathbf{1}}\right)$} & \multicolumn{2}{|c|}{ Heavy metal } & & \\
\cline { 2 - 4 } & Copper & Nickel & Lead & Zinc & \multirow{2}{*}{ PCP } \\
\hline 0 & $4.5 \pm 0.8$ & $4.5 \pm 0.8$ & $4.5 \pm 0.8$ & $4.5 \pm 0.8$ & $4.5 \pm 0.8$ \\
0.1 & $3.7 \pm 0.6$ & $3.9 \pm 0.7$ & $3.9 \pm 1.1$ & $3.0 \pm 0.5$ & $4.4 \pm 0.7$ \\
0.5 & $3.4 \pm 0.5$ & $4.2 \pm 0.6$ & $3.8 \pm 0.9$ & $3.1 \pm 0.6$ & $3.6 \pm 0.8$ \\
1.0 & $2.7 \pm 0.6$ & $4.2 \pm 0.6$ & $3.6 \pm 1.0$ & $3.3 \pm 0.6$ & $3.7 \pm 1.1$ \\
1.5 & $3.7 \pm 0.8$ & $4.3 \pm 1.1$ & $2.9 \pm 0.7$ & $3.7 \pm 0.7$ & \\
2.0 & $3.4 \pm 0.8$ & $4.3 \pm 0.7$ & $3.4 \pm 0.7$ & $4.0 \pm 0.8$ & \\
5.0 & & & & & $4.3 \pm 1.2$ \\
10.0 & & & & & $1.7 \pm 0.2$ \\
\hline
\end{tabular}

Mean values and standard deviation are shown.

could have negative effects on microorganisms. In contrast to the content of heavy metals, wood ash is also enriched with nutrients, which may have positive effects for the forest ecosystems. The most pronounced effects from wood ash application are an increased $\mathrm{pH}$ and an elevated content of cations. In order to study the effects of wood ash E. gracilis was used in both short- and long-term tests.

The tests were performed with ECOTOX and the time intervals for short-term tests were 0,24 , and $48 \mathrm{~h}$. In the experiments the effects of $\mathrm{pH}$ on cells of E. gracilis were tested which ranged from 7.0 to 11.2 . The effects of wood ash on motility parameters, when no adjustment of $\mathrm{pH}$ was made, showed strong inhibition at higher concentrations (above $10 \mathrm{~g} \mathrm{~L}^{-1}$, Fig. 21.3).

Especially upwards swimming and velocity after $48 \mathrm{~h}$ showed significant inhibition. Under natural conditions E. gracilis is limited to habitats with low acidity and has growth rates between 0.33 to 1.12 at $\mathrm{pH}$ values ranging from 2.0-6.0 [45]. Above $\mathrm{pH} 6$ the growth rate shows an inhibition which looks similar to the effects of high $\mathrm{pH}$ values on the motility parameters of E. gracilis. Similar results were shown in a study by Danilov and Ekelund [46]; cells of E. gracilis below pH 4 and above $\mathrm{pH} 8$ did not survive.

In the tests with wood ash and no adjustments of $\mathrm{pH}$ it is difficult to distinguish between effects from either high $\mathrm{pH}$ or from toxic compounds in the wood ash. However, when the $\mathrm{pH}$ of the wood ash solution was adjusted to $\mathrm{pH} 7$ the results showed a stimulation of the motility of E. gracilis (Fig. 21.4) [15]. Higher motility of E. gracilis in the presence of wood ash at an adjusted $\mathrm{pH}$ is probably an effect of the availability of nutrients in wood ash such as calcium $(\mathrm{Ca})$, potassium $(\mathrm{K})$, and magnesium (Mg) [15].

The observed differences in the motility parameters and growth rate are a combination of the addition of nutrients, organic compounds, and $\mathrm{pH}$ changes [45]. A long-term (7 days) growth test using E. gracilis with both adjusted $\mathrm{pH} 7$ and no 
(A)

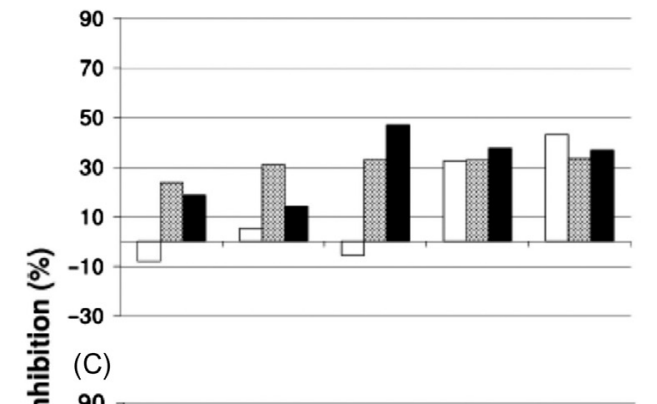

(D)

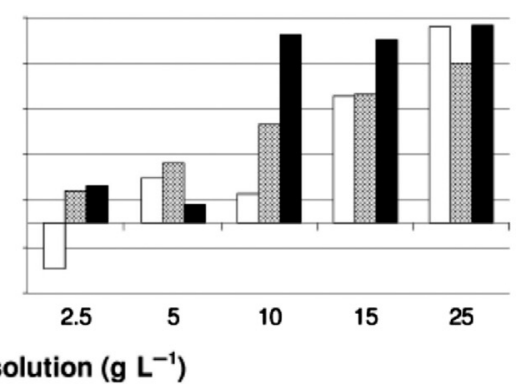

Figure 21.3 Inhibition of motility parameters in Euglena gracilis after $0 \mathrm{~h}$ (white bars), $24 \mathrm{~h}$ (gray bars), and $48 \mathrm{~h}$ (black bars) exposure to wood ash solution $\left(2.5,5,10,15,25 \mathrm{~g} \mathrm{~L}^{-1}\right)$; pH was not adjusted. Graphs show motility (A), upwards swimming (B), compactness (C), and velocity (D). Inhibition values are shown to those of the controls of each test.

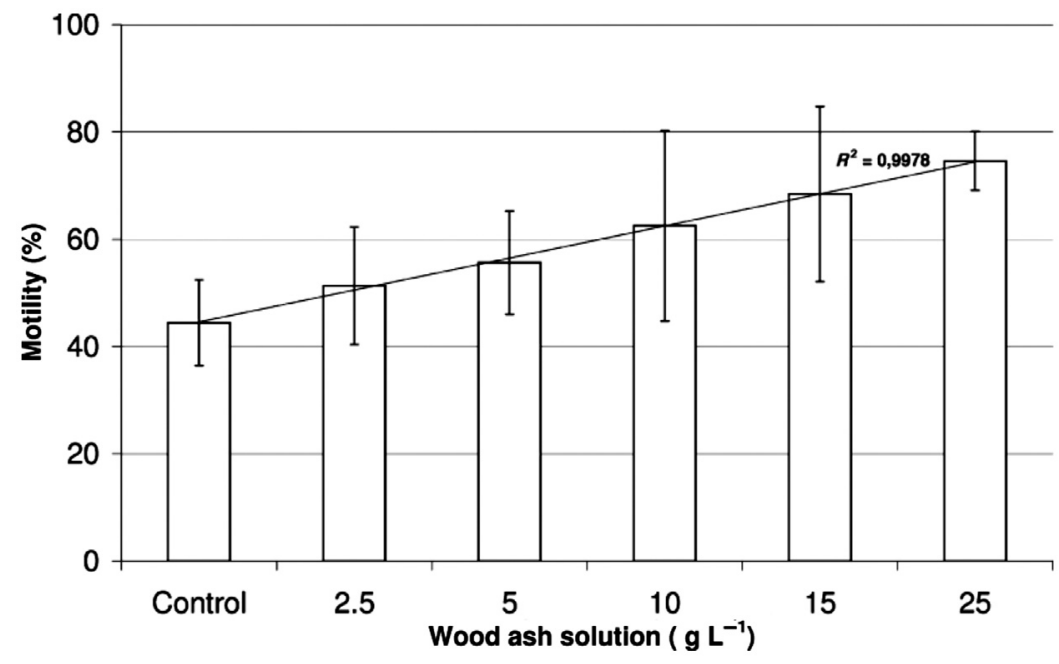

Figure 21.4 Mean values and standard deviation of Euglena gracilis motility tests in wood ash solution with $\mathrm{pH}$ adjusted. Controls were prepared with distilled water. 
adjustment of $\mathrm{pH}$ showed only a strong inhibition at the highest concentration of wood ash (15 and $\left.25 \mathrm{~g} \mathrm{~L}^{-1}\right)$ and a pH value of around 11 [15]. This indicates that E. gracilis has a high sensitivity at high $\mathrm{pH}$ values.

Copper $(\mathrm{Cu})$ is an essential microelement and has also been shown to have toxic effects at higher concentrations on different parameters in E. gracilis [26,46], The immediate response to copper was rapid when studying motility parameters with ECOTOX [26]. Already after 3 min copper showed a disturbance of the different motility parameters. The sensitivity of the different parameters was highest for motility followed by $r$-value, velocity, and upward swimming. The same order of sensitivity was found after $24 \mathrm{~h}$ but the $\mathrm{EC}_{50}$ values changed for motility and upward swimming in comparison to the short-term tests. The $\mathrm{EC}_{50}$ values for the short-term tests in this study were in the concentration range of from 19 to $50 \mathrm{mg} \mathrm{L}^{-1}$ which is much higher than the values found for copper in industrial wastewater in Pakistan where copper concentration varied from 0.01 to $0.18 \mathrm{mg} \mathrm{L}^{-1}$ [43]. In contrast, the results from the effects of wastewater in Pakistan on the different motility parameters of E. gracilis showed strong inhibition on cell compactness and gravitactic orientation. These negative effects of wastewater were not only due to copper but also to a large mixture of heavy metals including $\mathrm{Cd}, \mathrm{Fe}, \mathrm{Ni}, \mathrm{Cr}, \mathrm{Zn}$, and $\mathrm{Pb}$ [43].

\subsection{ECOTOX measurements in Egyptian lakes}

In the Northern part of Egypt near the Mediterranean coast several lakes and lagoons are located. Alexandria is the second largest city in Egypt and has about 4.1 million inhabitants (http://en.wikipedia.org/wiki/Alexandria). The lakes are polluted by industrial and domestic waste from the city and the surrounding areas. These wastes undergo only primary treatment, which removes suspended solid particles by filtration. Solubilized pollutants and toxic substances are not removed from the wastewater. Samples were taken from the wastewater treatment plant west of Alexandria before and after treatment and analyzed using the ECOTOX system.

Located to the Southeast of Alexandria is a large brackish lake (Lake Mariout), which has an area of ca. $250 \mathrm{~km}^{2}$. This lake is the source of fish (mainly Tilapia) for the local market in Alexandria. This economically important fish is heavily affected by pollution since about two thirds of the city sewage water is drained into the lake. Only half of this wastewater undergoes primary treatment before it is discarded into the lake. Over the years the input of almost untreated domestic waste and industrial effluents has resulted in elevated concentrations of heavy metals such as $\mathrm{Cd}, \mathrm{Pb}$, and $\mathrm{Cu}$, which accumulate in the water and sediments of lake Mariout [47].

The wastewater samples were collected in sterile 50-mL tubes and transferred rapidly to the laboratory where they were frozen until subsequent analysis. Prior to the ECOTOX measurements the samples were thawed at room temperature and subsequently centrifuged at $1000 \times \mathrm{g}$ for $5 \mathrm{~min}$. When necessary, the samples were diluted with deionized water before key chemical parameters were determined such as $\mathrm{pH}$, nitrate $\left(\mathrm{NO}_{3}{ }^{-}\right)$, nitrite $\left(\mathrm{NO}_{2}{ }^{-}\right)$, total and carbonate hardness using 
colorimetric tests (Merck, Germany). Dissolved oxygen was measured (DO-5509, Lutron electronics enterprise Co., LTD Taiwan).

Analysis of the input wastewater to the treatment plant using the ECOTOX instrument shows a significant pollution from mainly domestic effluents. As also found in other pollution analyses [48], gravitactic orientation ( $r$-value) shows the highest inhibition of up to $30 \%$ at a 1:1 dilution of the sample (Fig. 21.5A).
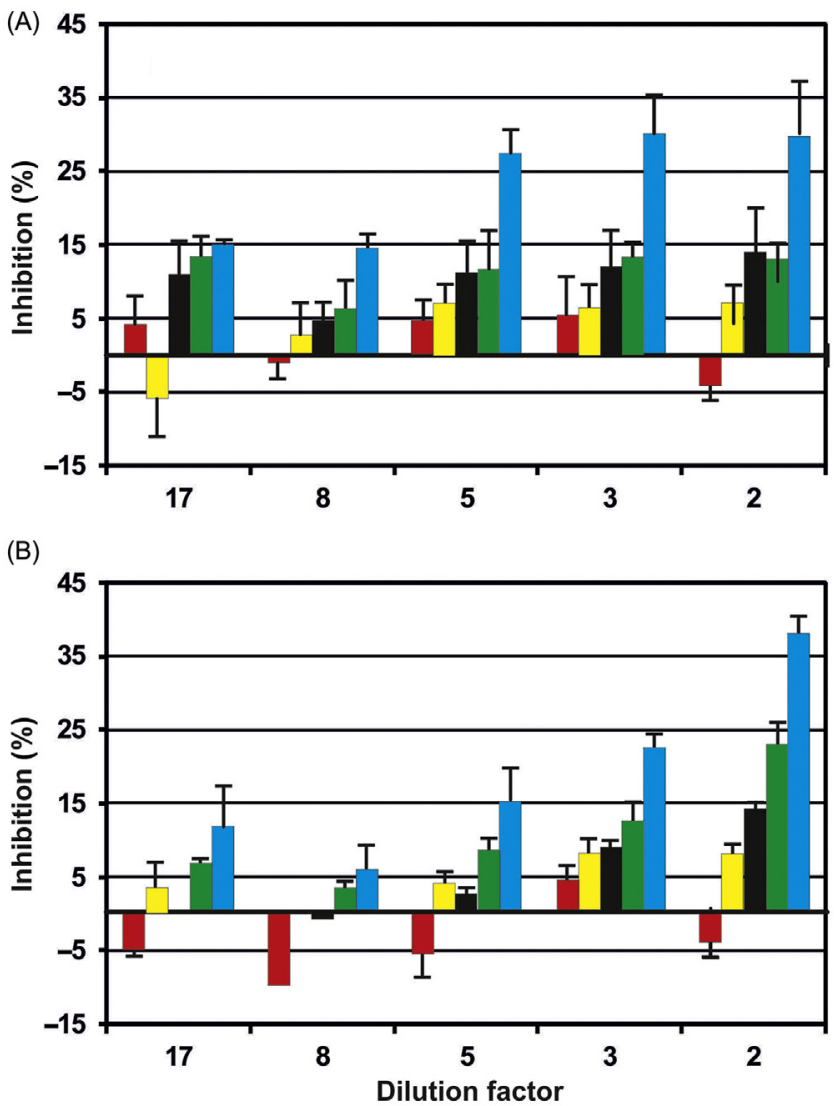

Figure 21.5 Inhibition (ordinate, \%) of movement and orientation parameters in Euglena gracilis by samples from a wastewater treatment plant in Alexandria at decreasing dilution comparing input (A) and output wastewater (B): compactness (red), motility (yellow), alignment (black), upward swimming (green), $r$-value (blue). Negative values indicate an augmentation in the parameter. Each data point represents the mean of three independent measurements with standard deviation.

Source: redrawn after Ahmed $\mathrm{H}$. Biomonitoring of aquatic ecosystems [ $\mathrm{PhD}$ thesis]. Erlangen-Nürnberg: Friedrich-Alexander-Universität; 2010 [49]. 
The other parameters (compactness, motility, alignment and upward swimming) are less affected and some are not significant. The comparison with the samples from the output from the wastewater plant after mechanical filtration of solid particles reveals that the toxicity is not reduced by the treatment (Fig. 21.5B). In fact, most of the inhibition values are even higher and the $r$-value shows an inhibition of $37 \%$ at the lowest dilution of 1:1. Among the lakes in the Nile Delta, Lake Mariout is the most polluted one [47]. It can be subdivided into four basins-the main basin, the fish farm basin, the Southwest basin, and the Southeast basin [50]. The main basin, located to the Northwest, contains the most polluted water. In addition to domestic wastewater, it receives industrial effluents and agricultural runoff. This combined pollution increases the sulfur concentration in the water and reduces the dissolved oxygen concentration. In contrast, the Southeast basin contains the least polluted water which enters from the El-Umoum drain and the Noubaria canal [50-52].

Even though the domestic and industrial wastewaters from Alexandria are being strongly diluted in the lake, water samples taken from the Southeast basin of Lake Mariout resulted in a significant inhibition of the tested endpoints. E.g., the $r$-value was inhibited by $11 \%-24 \%$ at the lowest and highest concentration, respectively, and also alignment and upward swimming were significantly impaired by increasing sample concentrations (Fig. 21.6A).

Samples from the main basin even resulted in a higher inhibition with the $r$-value being reduced by $15 \%-57.5 \%$ at the highest and lowest dilution, respectively (Fig. 21.6B). Also the motility, upward swimming, compactness, and alignment were strongly inhibited with increasing concentration of the polluted water.

For comparison, a pond with the name Rakta situated east of Alexandria was analyzed. This pond is strongly polluted by untreated effluents from nearby industries. At the highest dilution factors (17 to 5) no significant inhibition could be detected in all movement parameters (Fig. 21.7). At higher concentrations (lower dilution factors 2 and 3) motility was not significantly affected or even enhanced, while compactness, alignment, and upward swimming showed an inhibition of about $11 \%$. As in other tests of aquatic ecosystems, the $r$-value showed the highest inhibition of up to $29 \%$ by water samples of pond Rakta.

In addition to toxic pollutants such as heavy metals, organic and inorganic toxins, the physicochemical parameters of the water samples affect the inhibition of the movement, orientation and form parameters of the test organism E. gracilis in the ECOTOX measurements. These are summarized in Table 21.2. Especially the $\mathrm{pH}$ and total and carbonate hardness influence the water quality and affect the toxicity and thereby modify the biological risk [53]. In the analyzed samples $\mathrm{pH}$ and nitrite were in the normal range for freshwater lakes and drinking water. The samples from the input and output of the wastewater treatment plant as well as pond Rakta and the main basin of Lake Mariout had decreased dissolved oxygen (D.O.) values $\left(4.1-4.6 \mathrm{mg} \mathrm{L}^{-1}\right)$ as compared with the recommended values $(\geq$ $5 \mathrm{mg} \mathrm{L}^{-1}$ ). In addition, the analyzed samples had moderate to increased water hardness. 

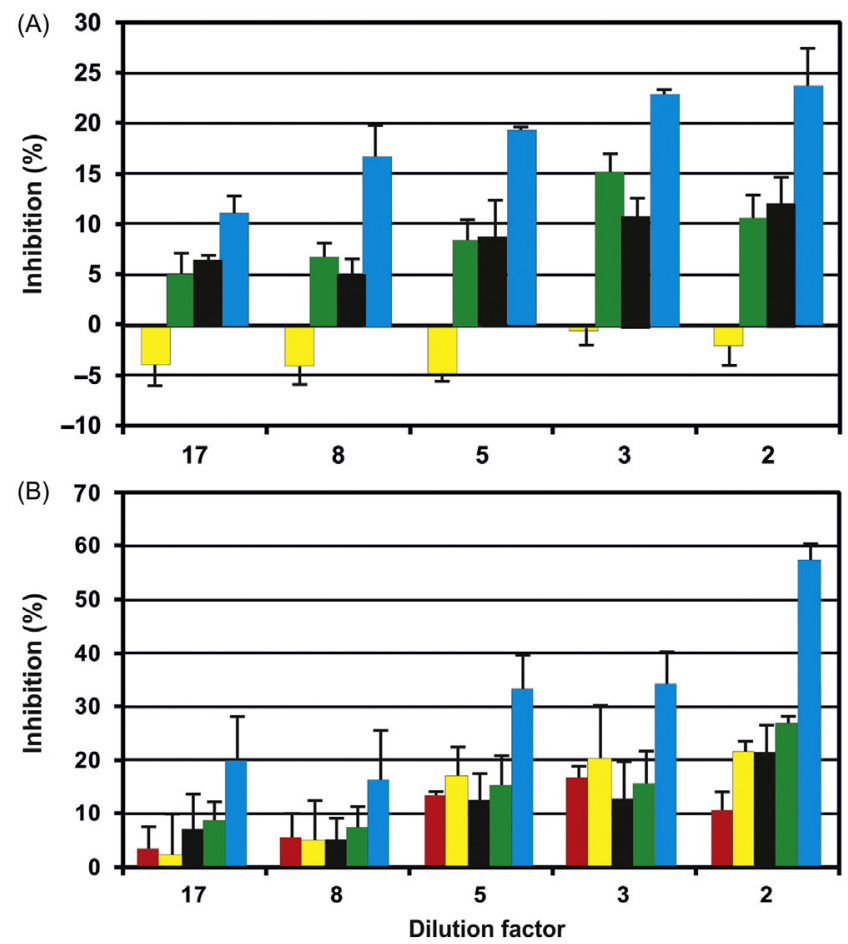

Figure 21.6 Inhibition (ordinate, \%) of movement parameters in Euglena gracilis by samples from the Southeast basin (A) and the main basin (B) of Lake Mariout at decreasing dilution: compactness (red), motility (yellow), alignment (black), upward swimming (green), $r$-value (blue). Negative values indicate an augmentation in the parameter. Each data point represents the mean of three independent measurements with standard deviation. Source: redrawn after Ahmed H. Biomonitoring of aquatic ecosystems [PhD thesis]. Erlangen-Nürnberg: Friedrich-Alexander-Universität; 2010.

\subsection{Conclusions}

Aquatic ecosystems are still affected by the contamination of industrial and municipal wastes. The pathways for pollutants and wastes to enter aquatic ecosystems are often via nonpoint sources, runoff from land or direct discharges from industries. Toxic compounds associated with these wastes are heavy metals, organic and inorganic compounds, pesticides and herbicides, which all may have negative impacts on aquatic organisms and function of aquatic ecosystems. Therefore it is of importance to establish monitoring systems which have the possibility and sensitivity to get an early warning signal of environmental damage. For testing the water quality the OECD guidelines promote microalgae and cyanobacteria as bioindicators [54]. 


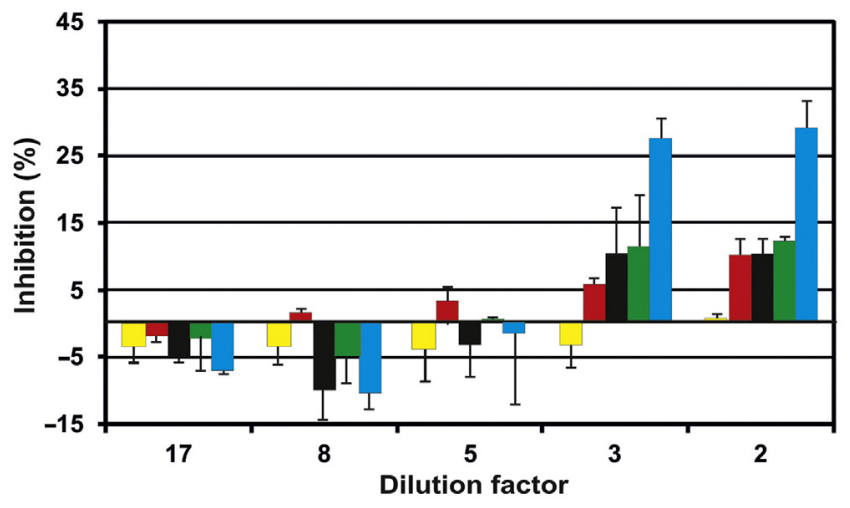

Figure 21.7 Inhibition (ordinate, \%) of the movement and orientation parameters of Euglena gracilis by samples from the Rakta pond at decreasing dilution: compactness (red), motility (yellow), alignment (black), upward swimming (green), $r$-value (blue). Negative values indicate an augmentation in the parameter. Each data point represents the mean of three independent measurements with standard deviation.

Source: redrawn after Ahmed H. Biomonitoring of aquatic ecosystems [PhD thesis].

Erlangen-Nürnberg: Friedrich-Alexander-Universität; 2010.

Table 21.2 Chemical parameters of wastewater samples from different sources near Alexandria, Egypt.

\begin{tabular}{|c|c|c|c|c|c|c|}
\hline $\begin{array}{l}\text { Source of } \\
\text { water } \\
\text { samples }\end{array}$ & pH & $\begin{array}{l}\mathrm{CH} \\
\left(\mathrm{mg} \mathrm{L} \mathrm{L}^{-1}\right)\end{array}$ & $\begin{array}{l}\text { TH }\left(\mathrm{mg} \mathrm{L}^{-1}\right. \\
\text { Ca) }\end{array}$ & $\begin{array}{l}\mathrm{NO}_{3}- \\
\left(\mathrm{mg} \mathrm{L}^{-1}\right)\end{array}$ & $\begin{array}{l}\mathrm{NO}_{2}- \\
\left(\mathrm{mg} \mathrm{L}^{-1}\right)\end{array}$ & $\begin{array}{l}\text { D.O. } \\
\left(\mathrm{mg} \mathrm{L} \mathrm{L}^{-1}\right)\end{array}$ \\
\hline \multicolumn{7}{|c|}{ Lake Mariout } \\
\hline Main basin & 8 & 160 & 143 & 0 & 0 & 4.6 \\
\hline $\begin{array}{l}\text { South east } \\
\text { basin }\end{array}$ & 8 & 160 & 143 & 10 & 0.5 & 6.6 \\
\hline Rakta Pond & 8 & 160 & 143 & 10 & 0 & 4.5 \\
\hline \multicolumn{7}{|c|}{ Wastewater treatment plant in Alexandria } \\
\hline Input & 8 & 160 & 143 & 0 & 0.5 & 4.1 \\
\hline Output & 8 & 160 & 143 & 0 & 0.5 & 4.1 \\
\hline
\end{tabular}

$\mathrm{TH}$, total hardness (mg L $\left.{ }^{-1} \mathrm{Ca}\right) ; \mathrm{CH}$, carbonate hardness $\mathrm{CaCO}_{3}\left(\mathrm{mg} \mathrm{L}^{-1}\right)$; D.O., dissolved oxygen $\left(\mathrm{mg} \mathrm{L}^{-1}\right)$.

In the OECD tests monitoring growth over a period of normally $72 \mathrm{~h}$ is recommended. As a complement to toxicological growth studies swimming behavior of motile microorganisms could be used. The present study shows that by using the ECOTOX method there is a possibility to calculate the number of motile cells, 
gravitaxis, the mean velocity, the compactness, and the precision of orientation of the cells. In most of the studies with the ECOTOX method the freshwater flagellate E. gracilis is used. This flagellate is very appropriate for this method due to its well-developed motility and precise gravitactic and phototactic orientation. Especially gravitactic orientation seems to be the most sensitive parameter when testing the effects of wastewater and heavy metals. The results indicate that ECOTOX, with its possibility of performing measurements within short periods (min), could be very useful in the future as an early warning biomonitoring system.

\section{References}

[1] Rossi SH. The toxic impacts of wastes from source to ultimate fate. In: Tapp JF, Hunt SM, Wharfe JR, editors. Toxic impacts of wastes on the aquatic environment. Cambridge: Royal Society of Chemistry; 1996. p. 1-8.

[2] Danilov RA, Ekelund NGA. Influence of wastewater from the paper industry and UV-B radiation on the photosynthetic efficiency of Euglena gracilis. J Appl Phycol 1999;11:157-63.

[3] Azizullah A, Jamil M, Richter P, Häder D-P. Fast bioassessment of wastewater and surface water quality using freshwater flagellate Euglena gracilis-a case study from Pakistan. J Appl Phycol 2014;26(1):421-31.

[4] Brack W, Ait-Aissa S, Burgess RM, Busch W, Creusot N, Di Paolo C, et al. Effectdirected analysis supporting monitoring of aquatic environments-An in-depth overview. Sci Total Environ 2016;544:1073-118.

[5] European Commission. Directive 2013/39/EU of the European Parliament and the Council of 12 August 2013 amending Directive 2000/60/EC and 2008/105/EC as regards priority substances in the field of water policy. Brussels: Official Journal of the European Union, 2013.

[6] Pettersson M, Ekelund NG. Effects of the herbicides Roundup and Avans on Euglena gracilis. Arch Env Contamin Toxicol 2006;50(2):175-81.

[7] Fai PB, Grant A, Reid B. Chlorophyll $a$ fluorescence as a biomarker for rapid toxicity assessment. Environ Toxicol Chem 2007;26(7):1520-31.

[8] Filimonova V, Gonçalves F, Marques JC, De Troch M, Gonçalves AM. Biochemical and toxicological effects of organic (herbicide Primextra ${ }^{\circledR}$ Gold TZ) and inorganic (copper) compounds on zooplankton and phytoplankton species. Aquat Toxicol 2016;177:33-43.

[9] Adams SM. Biomarker/bioindicator response profiles of organisms can help differentiate between sources of anthropogenic stressors in aquatic ecosystems. Biomarkers 2001;6(1):33-44.

[10] Adams S, Greeley M. Ecotoxicological indicators of water quality: using multiresponse indicators to assess the health of aquatic ecosystems. Water Air Soil Pollut 2000;123(1-4):103-15.

[11] Khan S, Cao Q, Zheng Y, Huang Y, Zhu Y. Health risks of heavy metals in contaminated soils and food crops irrigated with wastewater in Beijing, China. Environ Pollut 2008;152(3):686-92.

[12] Steffens J. The heavy metal-binding peptides of plants. Annu Rev Plant Biol 1990;41 (1):553-75. 
[13] Gutiérrez JC, Amaro F, Martín-González A. Heavy metal whole-cell biosensors using eukaryotic microorganisms: an updated critical review. Front Microbiol 2015;6:48.

[14] Khan Z, Rehman A, Hussain SZ. Resistance and uptake of cadmium by yeast, Pichia hampshirensis 4Aer, isolated from industrial effluent and its potential use in decontamination of wastewater. Chemosphere 2016;159:32-43.

[15] Aronsson AK, Ekelund NG. Effects on motile factors and cell growth of Euglena gracilis after exposure to wood ash solution; assessment of toxicity, nutrient availability and pH-dependency. Water Air Soil Pollut 2005;162(1-4):353-68.

[16] Busse MD, Ratcliff AW, Shestak CJ, Powers RF. Glyphosate toxicity and the effects of long-term vegetation control on soil microbial communities. Soil Biol Biochem 2001;33(12):1777-89.

[17] Ahmed H, Häder D-P. Rapid ecotoxicological bioassay of nickel and cadmium using motility and photosynthetic parameters of Euglena gracilis. Environ Exp Bot 2010;69:68-75.

[18] Feng C-Y, Wei J-F, Li Y-J, Yang Y-S, Wang Y-H, Lu L, et al. An on-chip pollutant toxicity determination based on marine microalgal swimming inhibition. Analyst 2016;141(5):1761-71.

[19] Ahlf W, Calmano W, Erhard J, Förstner U, editors. Comparison of five bioassay techniques for assessing sediment-bound. In: Environmental Bioassay Techniques and their Application: Proceedings of the 1st International Conference held in Lancaster, England, 11-14 July 1988; 2013: Springer Science \& Business Media.

[20] Chavan M, Thacker N, Tarar J. Toxicity evaluation of pesticide industry wastewater through fish bioassay.. IRA-Int J Appl Sci 2016;3:3.

[21] Udovic M, Drobne $\mathrm{D}$, Lestan $\mathrm{D}$. An in vivo invertebrate bioassay of $\mathrm{Pb}, \mathrm{Zn}$ and Cd stabilization in contaminated soil. Chemosphere 2013;92(9):1105-10.

[22] Cartwright NG, Lewis S. The role of environmental quality standards in controlling chemical contaminants in the environment. In: Tapp JF, Hunt SM, Wharfe JR, editors. Toxic impacts of wastes on the aquatic environment. Cambridge: Royal Society of Chemistry; 1996. p. 149-56.

[23] Li M, Gao X, Wu B, Qian X, Giesy JP, Cui Y. Microalga Euglena as a bioindicator for testing genotoxic potentials of organic pollutants in Taihu Lake, China. Ecotoxicology 2014;23(4):633-40.

[24] Stratton GW, Giles J. Importance of bioassay volume in toxicity tests using algae and aquatic invertebrates. Bull Environ Contam Toxicol 1990;44(3):420-7.

[25] Singh S, Singh N, Kumar V, Datta S, Wani AB, Singh D, et al. Toxicity, monitoring and biodegradation of the fungicide carbendazim. Environ Chem Lett 2016;14 (2):317-29.

[26] Ahmed H, Häder D-P. A fast algal bioassay for assessment of copper toxicity in water using Euglena gracilis. J Appl Phycol 2010;22(6):785-92.

[27] Brayner R, Couté A, Livage J, Perrette C, Sicard C. Micro-algal biosensors. Anal Bioanal Chem 2011;401(2):581-97.

[28] Leunert F, Grossart H-P, Gerhardt V, Eckert W. Toxicant induced changes on delayed fluorescence decay kinetics of cyanobacteria and green algae: a rapid and sensitive biotest. PLoS One. 2013;8(4):e63127.

[29] Herlory O, Bonzom J-M, Gilbin R. Sensitivity evaluation of the green alga Chlamydomonas reinhardtii to uranium by pulse amplitude modulated (PAM) fluorometry. Aquat Toxicol 2013;140:288-94.

[30] Sjollema SB, van Beusekom SA, van der Geest HG, Booij P, de Zwart D, Vethaak AD, et al. Laboratory algal bioassays using PAM fluorometry: effects of test conditions on 
the determination of herbicide and field sample toxicity. Environ Toxicol Chem 2014;33(5):1017-22.

[31] Machado MD, Soares EV. Use of a fluorescence-based approach to assess short-term responses of the alga Pseudokirchneriella subcapitata to metal stress. J Appl Phycol 2015;27(2):805-13.

[32] Ekelund NGA, Aronsson KA. Assessing Euglena gracilis motility using the automatic biotest ECOTOX application to evaluate water toxicity (cadmium). Vatten 2004;60: $77-83$.

[33] Giardi MT, Koblizek M, Masojıdek J. Photosystem II-based biosensors for the detection of pollutants. Biosens Bioelectron 2001;16(9):1027-33.

[34] Girling AE, Pascoe D, Janssen CR, Peither A, Wenzel A, Shäfer H, et al. Development of methods for evaluating toxicity to freshwater ecosystems. Ecotoxicol Environ Saf 2000;45.

[35] Araújo C, Souza-Santos L. Use of the microalgae Thalassiosira weissflogii to assess water toxicity in the Suape industrial-port complex of Pernambuco, Brazil. Ecotoxicol Environm Saf 2013;89:212-21.

[36] Sebaugh J. Guidelines for accurate EC50/IC50 estimation. Pharm Stat 2011;10 (2): $128-34$.

[37] Delignette-Muller ML, Forfait C, Billoir E, Charles S. A new perspective on the Dunnett procedure: filling the gap between NOEC/LOEC and ECX concepts. Environ Toxicol Chem 2011;30(12):2888-91.

[38] Haglund K. The use of algae in aquatic toxicity assessment. In: Round FE, Chapman DJ, editors. Progress in phycological research. Bristol: Lubrecht and Cramer Ltd; 1995. p. $181-212$.

[39] Tahedl H, Häder D-P. Fast examination of water quality using the automatic biotest ECOTOX based on the movement behavior of a freshwater flagellate. Water Res 1999;33:426-32.

[40] Tahedl H, Häder D-P. The use of image analysis in ecotoxicology. In: Häder D-P, editor. Image Analysis: Methods and Applications. Boca Raton, FL: CRC Press; 2001. p. 447-58.

[41] Tahedl H, Häder D-P. Automated biomonitoring using real time movement analysis of Euglena gracilis. Ecotoxicol Environ Saf 2001;48(2):161-9.

[42] Azizullah A, Richter P, Häder D-P. Effects of long-term exposure to industrial wastewater on photosynthetic performance of Euglena gracilis measured through chlorophyll fluorescence. J Appl Phycol 2014;27:303-10.

[43] Azizullah A, Richter P, Häder D-P. Sensitivity of various parameters in Euglena gracilis to short-term exposure to industrial wastewaters. J Appl Phycol 2012;24:187-200.

[44] Danilov RA, Ekelund NGA. Responses of photosynthetic efficiency, cell shape and motility in Euglena gracilis (Euglenophyceae) to short-term exposure to heavy metals and pentachlorophenol. Water Air Soil Pollut 2001;132:61-73.

[45] Olaveson MM, Nalewajko C. Effects of acidity on the growth rate of two Euglena species. Hydrobiologia 2000;433:39-56.

[46] Danilov R, Ekelund N. Effects of $\mathrm{pH}$ on the growth rate, motility and photosynthesis in Euglena gracilis. Folia Microbiol 2001;46(6):549-54.

[47] Saad MAH. Impact of diffuse pollution on the socio-economic development opportunities in the costal Nile delta lakes. In: Diffuse Pollution Conference; Dublin 2003. p. $81-86$.

[48] Azizullah A, Richter P, Jamil M, Häder D-P. Chronic toxicity of a laundry detergent to the freshwater flagellate Euglena gracilis. Ecotoxicology 2012;21(7):1957-64. 
[49] Ahmed H. Biomonitoring of aquatic ecosystems [PhD thesis]. Erlangen-Nürnberg: Friedrich-Alexander-Universität; 2010.

[50] Matta CA, Kheirallah A-MM, Abdelmeguid NE, Abdel-Moneim AM. Effects of water pollution in lake Mariut on gonadal free amino acid compositions in Oreochromis niloticus fish. Pak J Biol Sci 2007;10:1257-63.

[51] Adham K, Khairalla A, Abu-Shabana M, Abdel-Maguid N, Moneim AA. Environmental stress in lake Maryut and physiological response of Tilapia zilli Gerv. J Environ Sci Health Part A 1997;32(9-10):2585-98.

[52] Adham KG, Hamed SS, Ibrahim HM, Saleh RA. Impaired functions in Nile Tilapia, Oreochromis niloticus (Linnaeus, 1757), from polluted waters. Acta Hydrochim Hydrobiol 2001;29:278-88.

[53] Schuler LJ, Hoang TC, Rand GM. Aquatic risk assessment of copper in freshwater and saltwater ecosystems of South Florida. Ecotoxicology 2008;17(7):642-59.

[54] OECD Guidelines for the Testing of Chemicals 201: Freshwater Alga and Cyanobacteria. Growth Inhibition Test, OECD Guidelines for the Testing of Chemicals. 